\title{
The mean condensate heat resistance of dropwise condensation with flowing,
}

\section{inert gases}

\author{
C. W. M. van der Geld, H. J. H. Brouwers
}

Abstract The quantification of the condensate heat resistance is studied for dropwise condensation from flowing air-steam mixtures. Flows are essentially laminar and stable with gas Reynolds numbers around 900 and 2000 . The condensate shaping up as hemispheres on a plastic plane wall and the presence of inert gases make it possible that thermocapillary convection occurs making the resistance less than the mean condensate thickness (ca. $0.185 \mathrm{~mm}$ ) divided by the heat conduction coefficient. The analysis of experiments shows that the effective mean condensate resistance might indeed be less, by a factor of $0.8 \pm 0.2$. The analysis takes account of the sensible heat transfer which may be as large as $35 \%$ of the total heat transfer if inlet vapor concentration, $c_{\text {in }}$, is low (ca. 0.07). A method is presented to determine the gas-condensate interface temperature, $t_{i}$, that is needed in the analysis of the heat resistance. The highest temperature differences $\left(t_{i}-t_{w}\right), t_{w}$ being the mean temperature of the condenser plate at the gas side, have been found to occur for relatively high values of $c_{\text {in }}$ (ca. 0.3).

Der mittlere thermische Widerstand des Kondensats bei Tropfenkondensation aus einem Luft-Dampf-Gemisch

Zusammenfassung Es wird der thermische Kondensationswiderstand bei Tropfenkondensation aus einem strömenden Luft-Dampf-Gemisch untersucht. Die Strömung ist laminar und stationär mit Gas Reynolds-Zahlen zwischen 900 und 2000. In Anwesenheit von Inertgas kann thermokapillare Konvektion am halbkugelförmigen Kondensattropfen auftreten, wobei der thermische Widerstand kleiner ist, als der Quotient aus der mittleren Kondensatdicke (ca. 0,185 mm) und dem Wärmeübergangskoeffizienten. Die Analyse der Experimente

Received on 28 December 1994

Dr. C. W. M. van der Geld, Associate Professor

Eindhoven University of Technology

Faculty of Mechanical Engineering

W-Hoog 3.144

P.O. Box 513

NL-5600 MB Eindhoven

The Netherlands

Dr. H. J. H. Brouwers

University of Twente

NL-7500 AE Enschede

The Netherlands

The authors express their gratitude to C. de Jong, A. van Hoof, F. Ganzevles, D. Vlaicu and J. Schoonen for their contributions. zeigt, daß der effektive mittlere Kondensatwiderstand tatsächlich um einen Faktor 0,8 $\pm 0,2$ kleiner sein kann. Der Energieanteil infolge Kondensatunterkühlung wird berücksichtigt, er kann bis zu 35\% der gesamten Wärmeübertragung ausmachen, falls die Dampfkonzentration $c_{\text {in }}$ am Eintritt klein ist (ca. 0,07). Zur Bestimmung der in die Berechnung des thermischen Widerstandes eingehende Temperatur an der Grenzfläche zwischen Gas und Kondensat $t_{i}$, wird eine spezielle $\mathrm{Me}$ thode entwickelt. Die größte Temperaturdifferenz $\left(t_{i}-t_{w}\right)$ ergibt sich bei relativ hohen $c_{\mathrm{in}}$-Werten (ca. 0,3 ), wobei $t_{w}$ die mittlere Temperatur der Kondensatorplatte auf der Gasseite ist.

\section{Nomenclature}

surface area

$\left[\mathrm{m}^{2}\right]$

length of condenser plates

[m]

$C$ vapor mass fraction or vapor concen-

\section{tration}

$\frac{c_{p}}{d}$ specific heat at constant pressure mean condensate plate thickness from coolant to gas

ID diffusion coefficient

$D_{H} \quad$ hydraulic diameter, four times the cross-sectional area/the perimeter specific enthalpy

[kg/kg mixture] $\left[\mathrm{J} \cdot \mathrm{kg}^{-1} \mathrm{~K}^{-1}\right]$

[m]

$\left[\mathrm{m}^{2} \mathrm{~s}^{-1}\right]$

[m]

$E \quad$ distance between two condenser plates (Fig. 1)

$\left[\mathrm{J} \mathrm{kg}^{-1}\right]$

$f \quad$ Fanning friction factor

[m]

$F_{\text {conv }}$ convective heat transfer fraction (section 5)

$g$ acceleration due to gravity

$\left[\mathrm{m} / \mathrm{s}^{2}\right]$ heat transfer coefficient thermal conductivity

$\left[\mathrm{W} \cdot \mathrm{m}^{-2} \mathrm{~K}^{-1}\right]$ $\left[\mathrm{W} \cdot \mathrm{m}^{-1} \mathrm{~K}^{-1}\right]$ length or height of condenser plates (Fig. 1)

$\dot{m} \quad$ mass flux

$P \quad$ pressure

$q$ heat flux

$Q$ heat flow rate to one side of a condenser plate

[m]

$\left[\mathrm{kg} \cdot \mathrm{m}^{-2} \mathrm{~s}^{-1}\right]$

[Pa]

$\left[\mathrm{W} \mathrm{m}^{-2}\right.$ ] average radius of drop base

[W]

[m]

$R H \quad$ relative humidity

$t$ temperature

velocity in the channels

total mass flow rate

coordinate in direction of gas flow

(Fig. 1)

coordinate perpendicular to con-

denser plate (Fig. 1)

$\left[{ }^{\circ} \mathrm{C}\right]$

$\left[\mathrm{m} \mathrm{s}^{-1}\right]$

$\left[\mathrm{kg} \mathrm{s}^{-1}\right]$

$[\mathrm{m}]$

[m]

$z \quad$ coordinate in direction of liquid flow [m] 


\section{Greek letters}

$\begin{array}{lll}\delta & \text { condensate film thickness } & {[\mathrm{m}]} \\ \eta & \text { dynamic viscosity } & {[\mathrm{Pa} \cdot \mathrm{s}]} \\ \Theta & \text { correction factor } & \\ \lambda & \text { weighted mean condensate thickness } & {[\mathrm{m}]} \\ \rho & \text { mass density } & {\left[\mathrm{kg} \mathrm{m}^{-3}\right]} \\ \psi & \text { internal convection correction factor; } & \\ & \text { section } 5 & \\ \chi_{\text {conf }} & \text { configuration parameter; Sect. } 3.4 & \\ \xi & \text { wetted area fraction }\end{array}$

\section{Subscripts}

a inert gases without vapour, dry air

A condensate measured by weight and stopwatch

$b \quad$ bulk of the gas mixture

$B$ condensate measured by bulk vapor concentrations

c condensate; diffusional

conv due to convection

$g$ gas mixture

$g-i \quad$ gas to interface (Fig. 7)

$g-l \quad$ gas to liquid

$g-w \quad$ gas to gas-side wall surface (Fig. 7)

in inlet, the entry where $x=0$

$i$ interface

$l \quad$ liquid

$l-w_{l} \quad$ liquid to liquid-side wall of condenser plate (Fig. 7)

mean mean

out outlet, at $x=W$

$p_{l} \quad$ channel plate

$t$ thermal

$u$ frictional

$v \quad$ vapor

$w \quad$ plate surface of the heat exchanger at the gas side

$w_{l} \quad$ plate surface of the heat exchanger at the liquid side

$w_{l}-g \quad$ liquid-side plate surface to gas

$w_{l}-i \quad$ liquid-side plate surface to condensate-gas interface (Fig. 7)

$w_{l}-w \quad$ liquid-side plate surface to gas-side plate surface (Fig. 7)

wet wetted part

Superscripts

- $\quad$ averaged over entire condenser plate area

\section{Acronyms}

$\mathrm{Nu} \quad$ Nusselt number, $h \cdot D_{h} / k$

Pr Prandtl number, $\eta \cdot c_{p} / k$

Re Reynolds number, $v \cdot D_{H} \cdot \rho / \eta$

Sc Schmidt number, $\eta / \rho \mathbb{D}$

Sh Sherwood number, $g_{m} \cdot D_{h} / \rho \mathbb{D}$

\section{1}

\section{Introduction}

One way to enhance the reduced heat transfer rate during the heat recovery from corrosive process gases and extraction of condensable toxic components via the condensate is to create dropwise rather than filmwise condensation. For this purpose water should have a high contact angle of ca. $90^{\circ}$ on the condenser surface material, different from commonly applied materials. Coatings of plastics, although promising and often ap- plied, do not seem reliable enough to guarantee good lifetime performance. A fully plastic compact heat exchanger was developed in the eighties by AKZO NOBEL's research institute ${ }^{1}$. This crossflow heat exchanger is made entirely from PolyVinyliDene Fluoride (PVDF) on which water has a contact angle of ca. $90^{\circ}$. It is made of 96 plates with small coolant channels and thin walls. Gas and liquid flows entering the heat exchanger spread equally over the channels and are laminar with Reynolds numbers in the range $200<R e<2000$. Bulk values of temperature and water-vapor mass fraction are employed to render the problem into a two-dimensional one. If heat transfer without condensation is considered this approach results in a set of governing differential equations with solution wellknown from literature. In the case of partial vapor condensation the temperature at the condensate-gas interface is nonuniform.

In an earlier study of condensation in compact heat exchangers [1], condensation was assumed to be filmwise and emphasis was laid on the proper deduction of bulk values and the accounting for fog formation. In the present study, extensive sets of new measurements of dropwise condensation from air-steam mixtures flowing in two, especially designed PVDF heat exchangers are analysed in order to determine the condensate heat resistance. Several investigators $[2,3]$ presented experimental evidence for the insulating effect of condensate drops in static vapor environment.

The heat transfer resistance of the condensate not only depends on drainage and the wetted area fraction, but also on the condensate interface temperature, $t_{i}$. This paper presents a method to determine $t_{i}$ from parameters measured at the inlet and the outlet. The convective (sensible) heat transfer coefficient from the gas to the adhering drops is used in this method. Many studies in the literature consider pure steam condensation in which convective heat transfer is negligible, either for isothermal plates [2] or for nonisothermal plates [4]. The present paper concerns air-steam condensation on nonisothermal plates in which convective heat transfer cannot be neglected. It is therefore analysed with the aid of a finite element computation and a comparison of pressure drops taking advantage of results from the literature obtained for similar flow situations. This analysis justifies a procedure to compute the average value of the convective heat transfer coefficient from its average value in measurements without condensation. These measurements have been performed. The interface temperature has subsequently been determined for a large number of flow conditions.

The interface temperatures are used to quantify the heat resistance of the condensate. The hemispherical condensate shape and the presence of inert gases allow for temperature gradients to occur at the condensate-gas interface of a drop. These gradients actually do occur, as has been demonstrated experimentally [5]. If thermocapillary convection would result from these gradients the condensate heat resistance would be reduced [6]. No other direct experimental quantification of thermocapillary effects during condensation has been found in the literature.

I Maximum operation temperature is limited to $200^{\circ} \mathrm{C}$, if properly cooled. 


\section{Experimental}

Twenty test runs to quantify heat resistances are performed with two sets of 48 condenser plates separately to increase accuracy. These are the two sections of the 'mixed cross-flow' setup in Fig. 1.

To increase the gas Reynolds number substantially to investigate the effect of the increased convective heat transfer, additionally a set of 24 condenser plates is measured in pure crossflow. Another set of 24 plates in pure crossflow (see the 'pure cross-flow' set-up in Fig. 2) is measured separately to increase accuracy.

This section describes the main features of the heat exchanger geometries and the test rig and an assessment of the measuring accuracies.

\section{1}

\section{Plastic heat exchanger geometry}

The two heat exchanger test stands have extensively been reported before [7]. The most important aspects are summarized below.

Lengths and thicknesses of a separate condenser plate have been measured with a Zeiss UMM 200 microscope. Mean con-

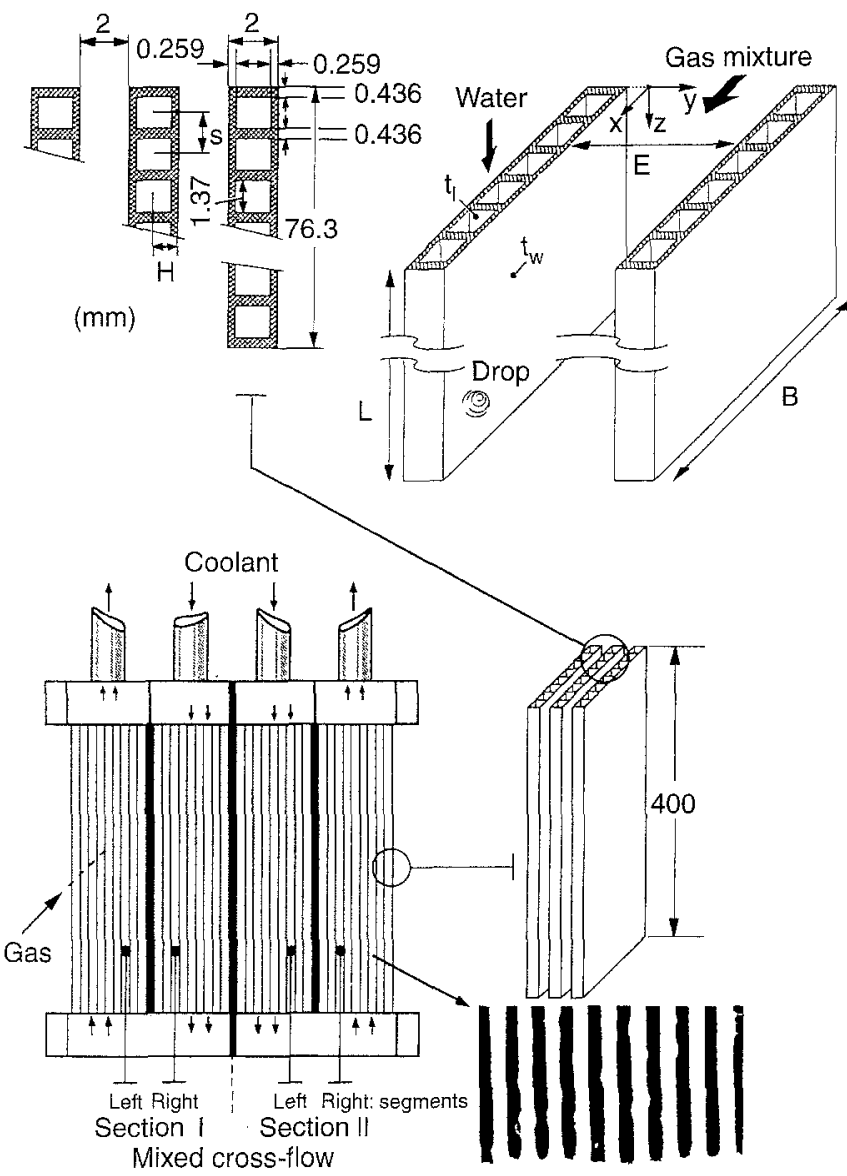

Fig. 1. Schematic of flows in mixed cross-flow compact heat exchanger and some dimensions. Small photograph of condensation on PVDF plates, made from the downstream side. Large drops are clearly seen to adhere to the plates.

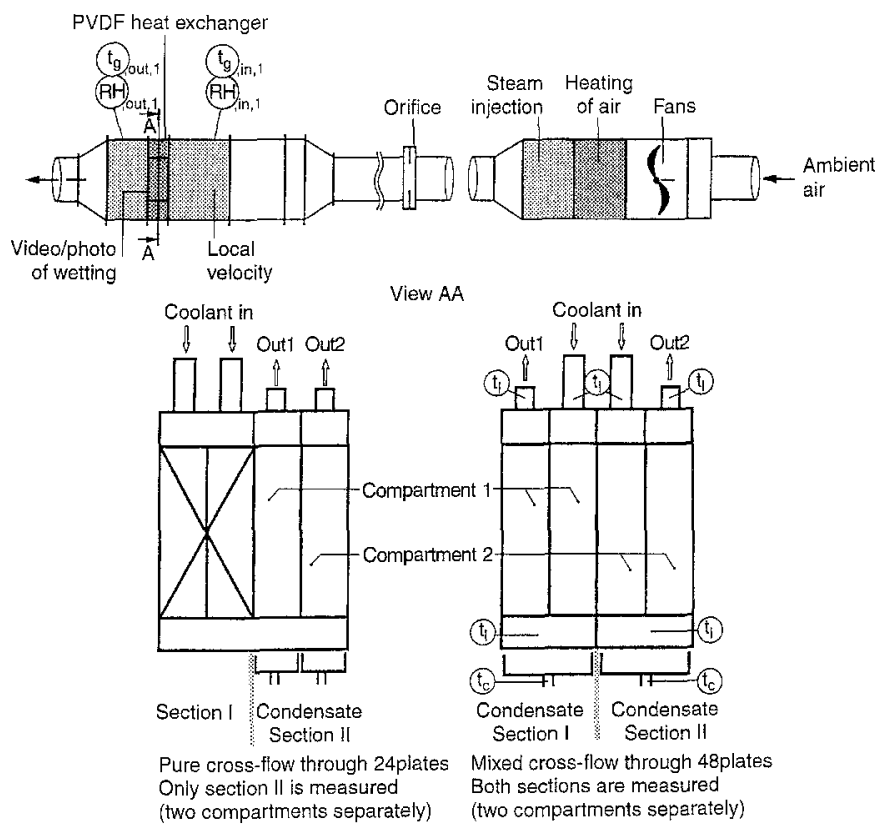

Fig. 2. Schematic of test rig; definition of pure cross-flow and mixed cross-flow heat exchangers

denser plate thickness between the coolant and the air is $0.259 \pm 0.003 \mathrm{~mm}$ (see Fig. 1), from 21 data. It is noted that the heat exchangers of this study are different from the one used in an earlier study [1]. Each type of heat exchanger comprises 96 condenser plates. Each plate comprises 42 approximately square channels of $1.37 \times 1.37 \mathrm{~mm}^{2}$ with rounded corners. The coolant flows through the inner channels in directions indicated in Fig. 2. Section II of the pure cross-flow arrangement comprises two segments that are individually measured and named compartments of the pure cross-flow heat exchanger. Sections I and II of the mixed cross-flow arrangement, see Figs. 1 and 2 , are individually measured and named compartments of the mixed cross-flow heat exchanger. So a compartment of the pure cross-flow type comprises one segment and a compartment of the mixed cross-flow type comprises two segments. No gas passes through section I of the pure cross-flow exchanger to prevent undesirable heating of the coolant.

Glass plates up- and downstream of the heat exchanger separate compartments. The condensate of each compartment is gathered directly downstream of the heat exchanger in a glass enclosure with low borders and a hole in the center (see Fig. 2). From there it is collected in a glass vessel, during 2 to 7 minutes, measured by a stopwatch. This yields a direct measure of the condensate mass flow rate denoted with $W_{c_{A}}$ (relative accuracy $5 \%$ ). In a converging part of the lead towards the glass vessel the mixing cup condensate temperature is measured.

\section{2}

\section{Test rig}

Tests are performed at ambient pressure in a low speed wind tunnel with an entire length of about $16 \mathrm{~m}$. Two fans, $0.88 \mathrm{~kW}$ each, blow air through two metal heat exchangers. Superheated steam of $150^{\circ} \mathrm{C}$ at a maximum pressure of $0.8 \mathrm{MPa}$ (temperature $140^{\circ} \mathrm{C}$ ) is supplied to these heat exchangers and to a steam 
injector. Gas mixtures at different temperatures and with measured vapor mass fractions below $90 \% \mathrm{~kg} /(\mathrm{kg}$ mixture) are created in this way. Flow rate is calculated from the pressure drop over an orifice plate with $4 \mathrm{~m}$ straight inlet and $2 \mathrm{~m}$ straight outlet pipe (DIN 1952).

A PVDF heat exchanger is mounted in a rectangular chamber with $10 \mathrm{~mm}$ thick heat resistant glass walls and a total length of $2.8 \mathrm{~m}$. At the entrance a calming section occurs with a flow straightener to avoid preference flows. The entire test rig is thermally insulated with removable covers at the glass chamber. Only stationary conditions are measured.

Temperature is measured with mercury thermometers (accuracy $0.1^{\circ} \mathrm{C}$ ), resistance thermometers and with thermocouples (encapsulated chromel-alumel, $\emptyset 1 \mathrm{~mm}$ ). Relative humidity is measured with Vaisala HMP-135 Y devices (relative accuracy $1 \%)$. Two rotameters measure the coolant volume flow rate $\left(2.7 \mathrm{~m}^{3} / \mathrm{hr}\right.$ maximum, accuracy $\left.0.02 \mathrm{~kg} / \mathrm{s}\right)$; coolant is demineralized water.

Inlet conditions are in the following ranges: Coolant mass flow rate, $W_{l}=0.45$ (pure crossflow) and $0.72 \mathrm{~kg} / \mathrm{s}$; liquid temperature, $t_{i}=20^{\circ} \mathrm{C}$; relative humidity, $R H, 25$ to $95 \%$; gas temperature, $t_{g}$, 65 to $100^{\circ} \mathrm{C} ; W_{g}=0.17$ to $0.21 \mathrm{~kg} / \mathrm{s}$ for each compartment.

\section{3}

\section{Assessment of measurement accuracies}

Two independent ways to measure the condensate mass flow rate, $W_{c}$, are compared in order to validate the accuracy of $W_{c}$ and of the vapor concentrations.

The condensate mass flow rate is measured directly as described above, yielding $W_{c_{A}}$. The condensate mass flow rate is alternatively determined from the total inlet gas flow rate, $W_{g_{\mathrm{in}}}$, and the inlet and outlet vapor concentrations, $c_{\text {in }}$ en $c_{\text {out }}$ respectively:

$W_{c_{B}}=\frac{W_{g_{\text {in }}}}{2} \frac{c_{\text {in }}-c_{\text {out }}}{1-c_{\text {out }}}$

The factor of 2 accounts for the number of compartments. This equation easily follows from the conservation of mass for the inert gases and vapor ${ }^{2}$.

Figure 3 shows a typical comparison of the condensate mass flow rates; $A_{w}$ denotes the wall surface area at the gas side of one compartment. Errors indicated are computed with the method of Kline and McClintock [8]. The agreement between the two measurement principles A and B is good. The values of $W_{c_{B}}$ are considered to be more accurate in view of the computed errors. Good agreement is also found for compartment 1 of the mixed cross-flow unit and for both compartments of the pure cross-flow exchanger. The condensate mass flow rate $W_{c_{B}}$ will henceforth be used in the analysis and denoted with $W_{c}$.

Figure 3 also shows heat released by the gas as defined by $q_{g}=Q_{g} / A_{w}$ and

$Q_{g} \stackrel{\text { def }}{=} W_{g_{\text {in }}} \cdot e_{g_{\text {in }}}-\left(W_{g_{\text {in }}}-W_{c}\right) \cdot e_{g_{\text {out }}}$

It increases with condensate mass flux as expected.

Error computation is performed with the following measuring accuracies. Pressure drop, $\Delta P, \pm 4 \%, t_{g}, \pm 0.5^{\circ} \mathrm{C}, R H, \pm 1 \%$,

$\left.\overline{W_{\text {gin }}\left(1-c_{\text {in }}\right)}\right)=W_{\text {govt }}\left(1-c_{\text {out }}\right)$ and $W_{g_{\text {in }}} \cdot c_{\text {in }}=W_{\text {gout }} \cdot c_{\text {out }}+W_{c}$

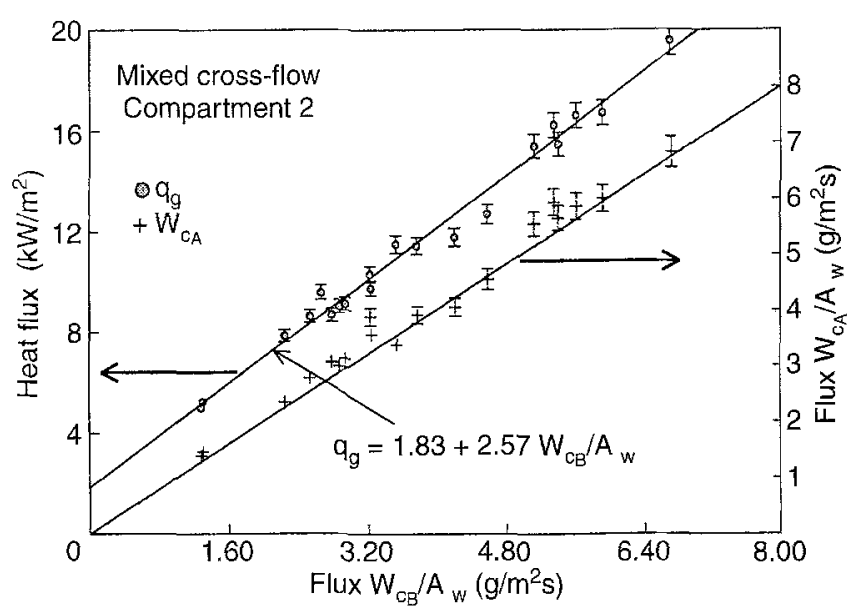

Fig. 3. Heat released by gas in one compartment and condensate flux comparison

$t_{c}, \pm 0.2^{\circ} \mathrm{C}$. If results are given for one compartment only, results for other compartments are similar.

Let $Q_{l}$ denote the heat flow rate to the coolant. The error $\left|\left\{Q_{g}-W_{c} \cdot e_{c_{\mathrm{cout}}}-Q_{l}\right\} / Q_{l}\right|$ is less than $3 \%$ for $73 \%$ of all double pass measurements and less than $7 \%$ for $89 \%$ of these measurements. $Q_{g}$ was not systematically less nor greater than $Q_{l}$.

\section{3}

Determination of the sensible heat transfer to the condensate In this section the convective heat transfer coefficient from the gas to the wall and the condensate drops is examined and quantified.

\section{1}

\section{The dependance of the average convective heat transfer on flow stability}

Fiebig et al. [9], presented an interesting analysis of the spatial and time behaviour of the Nusselt number in laminar flow over periodically arranged cavities. A boundary layer starts from flow obstructions such as ribs and separates flow regimes. Heat transfer in the separated zones is poor due to an inadequate exchange of fluid. Regions with flow onto the wall have a good heat transfer. It was concluded that the heat transfer is sensitive to flow conditions. The time and space averaged Nusselt number, $\overline{N u_{g}}$, approximately equals that for a plane channel wall, $\overline{N u_{0}}$, if the separated zones are stable. At a rib height of $35 \%$ of the channel height they found that the pressure drop is about twice the plane wall value and that $\overline{N u}_{g}$ is still approximately equal to $\overline{N u_{0}}$. For bigger rib heights flow oscillations set in and heat transfer increases. These oscillations correspond to the frequent detaching of the vortex structures downstream of the flow obstructions.

In a condensing environment a similar finding was reported by $\mathrm{Hu}$ et al. [10]. Small-scale structures, horseshoe vortices, downstream of condensate drops induce local heat transfer variations. Again, the net impact to air-side heat transfer was found to be coupled to flow conditions.

Hemispheres of variable size and location (condensate drops) at a plane wall create 3-D flow that is difficult to analyse in detail, both numerically and experimentally. A 2-D analogon 
is numerically studied below in order to verify if flow is stable. The total pressure drop over the compact heat exchanger is analysed in Sect. 3.3 in order to verify the absence of flow oscillations experimentally.

\section{2}

\section{Numerical analysis of flow stability} and condensate temperature drop

A 2-D computation with a finite element method is performed to investigate temperature variation in a drop and to investigate the stability of the wake downstream of the drop. 12000 Elements of varying shape, connecting a hemicircle with two plane walls, and 11000 nodes are employed, see Fig. 4. Inlet velocity is $5.5 \mathrm{~m} / \mathrm{s}$, typical for our measurements. The condensation enthalpy release is simulated by a homogeneously distributed heat source on the surface $\left(5.99 \mathrm{~kW} / \mathrm{m}^{2}\right)$ corresponding to a condensate mass flux that has actually been measured for these inlet conditions. The no-slip condition is assumed to hold at the drop suface in view of the gas-water viscosity ratio of about $10^{-7}$. Conduction in the PVDF plate is computed (see Fig. 4). The wall temperature just underneath the plate, $t_{w_{i}}$ is taken to increase linearly in gas flow direction from 24 to $29^{\circ} \mathrm{C}$ over $76.3 \mathrm{~mm}$. The drop base radius, $R$, is $0.5 \mathrm{~mm}$.

The wake region is found to be large, at relatively low temperature, and stable, see Fig. 5. The stability indicates that severe flow oscillations are unlikely. This has been verified for several velocities with two different programmes, FIDAP ${ }^{\text {TM }}$ Fig. 5 and FLUENT ${ }^{\mathrm{TM}}$ [7]. It is noted that unstable flow regimes such as the von Karman vortex street downstream of a cylinder have easily been reproduced with FIDAP ${ }^{\mathrm{TM}}$ for much lower Reynolds numbers. In the computations the distance between drops has been set much larger than the actual one. The stability of the separated zones is even higher for the more closely packed drops that occur in practice.

A varying gas-liquid interfacial temperature, $t_{i}$, corresponds to a varying partial vapor pressure. The presence of inert gases

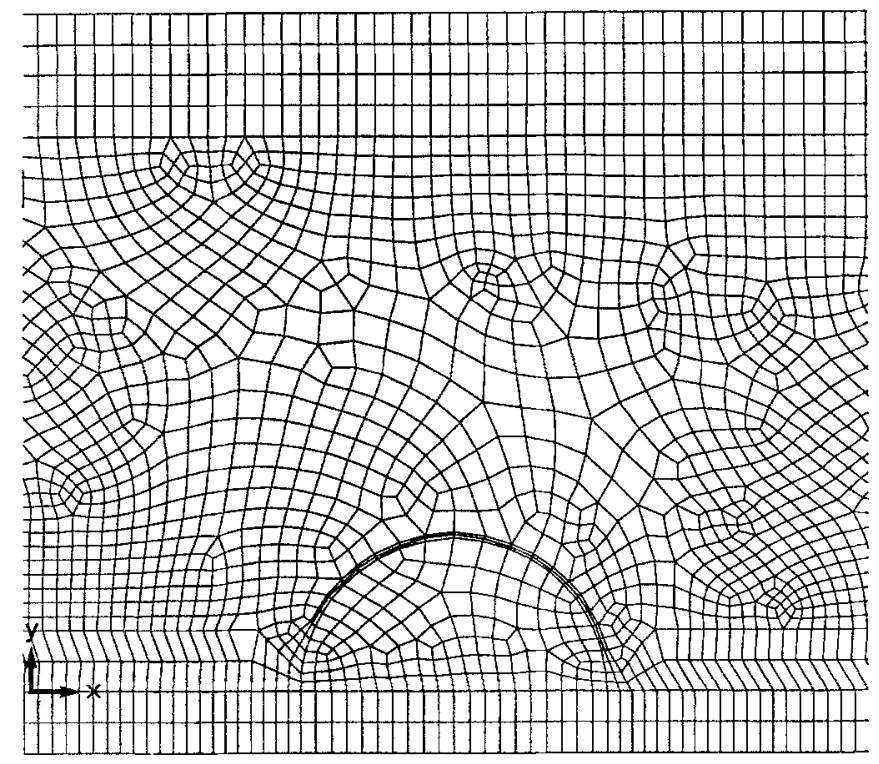

Fig. 4. Schematic plan-view of the composite grid used for computation
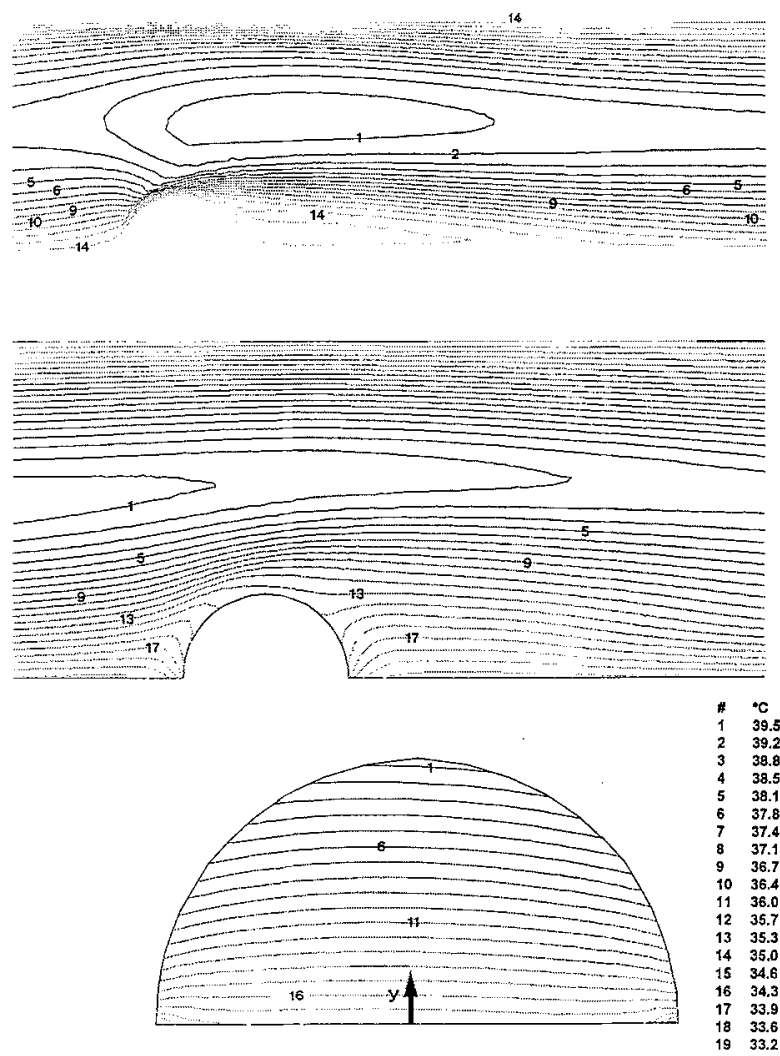

Fig. 5. Finite element computation of 2-D temperature profiles in and around a static drop with radius $0.5 \mathrm{~mm}$ on a $0.2 \mathrm{~mm}$ thick PVDF plate with bottom temperature linearly increasing in gasflow direction from 24 to $29^{\circ} \mathrm{C}$. A uniform line heat source of $5.99 \mathrm{~kW} / \mathrm{m}^{2}$ is distributed over the drop surface to simulate condensation enthalpy release. The degree of grey-black indicates the value of the quantity plotted

makes it possible that interfacial temperature differences occur at the drop surface. The temperature in the hemicylindrical drop is found to vary approximately linearly with height, $y$, above the wall ${ }^{3}$ (see Fig. 5). Let $\lambda$ denote the average value of the condensate height $y_{i}$, which is the height of the interface, to be quantified in section 4.1. The local temperature drop $\Delta t$, defined as $t_{i}-t_{w}$, is proportional to $y_{i}$. The ratio $k_{c} \Delta t / y_{i}$ is therefore constant and equal to $k_{c}\left(\overline{t_{i}}-t_{w}\right) / \lambda$ as follows by averaging $k_{c} \cdot \Delta t$. This ratio, if used to approximate the local heat flux and integrated over one unit area of drop base, yields the heat flux through the drop that, by definition of $h_{c}$, is equal to $h_{c}\left(\overline{t_{i}}-t_{w}\right)$. Thus $h_{c} \simeq k_{c} / \lambda$. This result shall be used in section 5 .

According to numerical computations, the maximum temperature drop is ca. $6^{\circ} \mathrm{C}$ for $R=0.5 \mathrm{~mm}$ and hence ca. $3.6^{\circ} \mathrm{C}$ for the average value $R=0.30 \mathrm{~mm}$. If these results for a $2-\mathrm{D}$ geometry can be extrapolated to a 3-D hemisphere, the value of the average temperature drop, averaged over all drops, would be about $2.2^{\circ} \mathrm{C}$. Note that the interface temperature variation is entirely dictated by the imposed, uniform condensation enthalpy release and the computed sensible heat transfer to the droplet. These estimates will be valuable for the analysis of the condensate heat resistance of Sect. 5 .

3 This similarity of upstream and downstream sides is lost if the homogeneous heat source is omitted from the computation, as has been verified by other computations. 
3.3

\section{Experimental analysis of flow stability by a pressure drop comparison}

In this section the measured pressure drop in a gas channel with walls covered with drops is compared with the pressure drop in a flat gas channel. For measurements without condensation the pressure gradient is given by

$\frac{\mathrm{d} P}{\mathrm{~d} x}=-2 \rho_{g} f \frac{1}{D_{H_{g}}} v_{g}^{2}$

The Fanning friction factor, $f$, is theoretically [11] given by

$f \approx \frac{41}{R e_{g}}$ for $B \approx 0.01 \cdot D_{H_{g}} \cdot R e_{g}$

where the factor 41 weakly depends on Reynolds number, $R e_{g}$, defined by $R e_{g} \stackrel{\text { def }}{=} v_{g} D_{H_{g}} \rho_{g} / \eta_{g}$ with $\eta_{g}$ the dynamic viscosity of the gas and $D_{H_{g}}$ the hydraulic diameter equal to $2 E$. If the pressure gradient is constant it is easily integrated in flow direction.

This yields $\frac{\mathrm{d} P}{\mathrm{~d} x} \approx \frac{\Delta P}{B}$ and after rearranging terms an expres-

sion for $f$ in terms of parameters that are all directly measured.

Figure 6 shows a typical comparison of theoretical and experimental Fanning friction factors. For the measurements without condensation there is good agreement in view of the $(41 / R e)$-fit. The condensation mass flux affects friction in a way described in an earlier study [12]. The pressure gradient de-

rived is rewritten, making use of $\frac{\mathrm{d} P}{\mathrm{~d} x} \approx \frac{\Delta P}{B}$, into

$f=-\frac{2 \dot{m}_{c}}{\rho_{g} v_{g}} / \ln \left(1+1 /\left\{2 \chi+\frac{D_{H_{g}}}{B} \frac{1}{4} \frac{1}{v_{g}} \frac{1}{\dot{m}_{c}} \Delta p\right\}\right)$

an expression for $f$ in terms of parameters that are all directly measured ( $\chi$ is a known constant, 1.2 in our application). The experimental results for $f$ are shown in Fig. 6 and fitted as $70 / R e$. The friction factor does not depend on process conditions but merely on geometry. Due to the presence of drops on the wall the measured value is about $7 / 4$ times the one without condensation.

The fact that the friction factor with drops is only $\frac{7}{4}$ th of the one without drops, as in the stable flow case of Fiebig et al. [9],

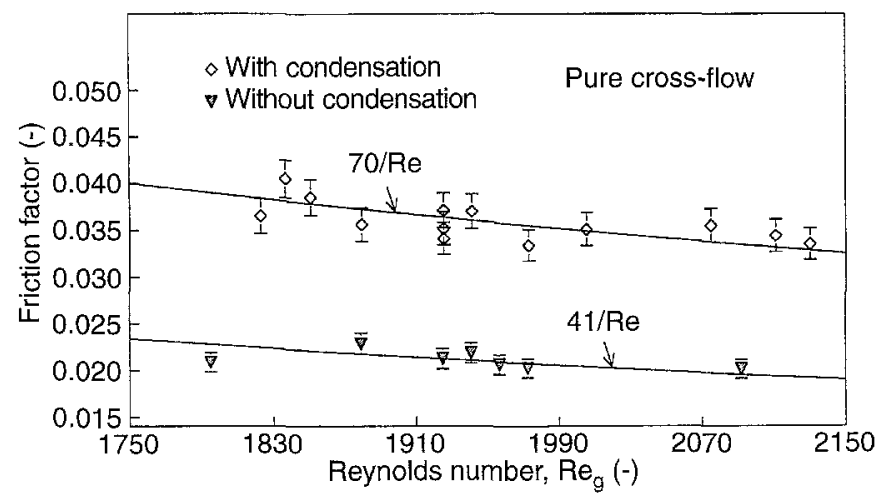

Fig. 6. Experimental and theoretical friction factors
$-N \times \times \times \times \times \times \times \times \times \times \times \times \times \times \times \times \times \times \times \times \times \times \times \times \times$

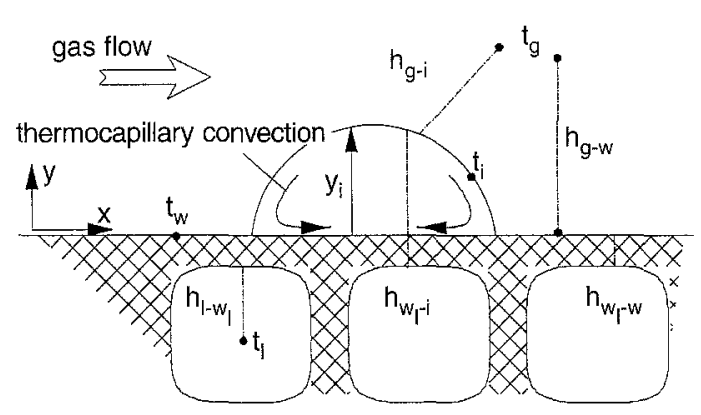

Fig. 7. Schematic of temperatures and heat transfer coefficients. Gravity acts normal to the plane of the drawing

confirms the finding of Sect. 3.2 that flow is without severe oscillations and that the wake structures are stagnant. It is therefore concluded that the mean Nusselt number, $\overline{N u_{g}}$, is well approximated by $\overline{\mathrm{Nu}}$, the value without condensation. The error of this approximation is estimated to be 5 to $10 \%$, about the usual measurement accuracy. In the sequel, the notation $\mathrm{Nu}_{g}$ will replace $\overline{N u}_{g}$ since only average values will be considered.

Upstream of a drop heat transfer is enhanced by flow onto the surface and by locally higher gas velocities whereas downstream convective heat transfer in the separated zone is poor (Fig. 5). The mean value of the convective heat transfer coefficient from the gas to the drop interface, $h_{g-i}$ (see Fig. 7 ), is therefore expected to be close to the mean value of $h_{g}$ as derived from $N u_{g}$. This result is employed in the computation of interface temperatures (Sect. 4.2).

\section{4}

\section{Experimental determination of the average Nusselt number}

Experiments without condensation have been performed to establish correlations for heat transfer from the gas to the wall, to be used in Sect. 4.2.

The usual definitions for $\Delta t_{\ln }$ and $\Delta t_{\text {mean }}$ are employed in the following defining equation of $h_{g-l}$

$$
\begin{aligned}
& Q_{c}=h_{g-l} \cdot A_{w} \cdot \chi_{\text {conf }} \cdot \Delta t_{\mathrm{ln}}=h_{g-l} \cdot A_{w} \cdot \Delta t_{\text {gem }} \\
& \Delta t_{\mathrm{ln}}=\left(\Delta t_{e}-\Delta t_{f}\right) / \ln \left(\frac{\Delta t_{e}}{\Delta t_{f}}\right) \\
& \Delta t_{e} \stackrel{\text { def }}{=} t_{g_{\text {in }}}-t_{l_{\text {out }}} \wedge \Delta t_{f} \stackrel{\text { def }}{=} t_{g_{\text {out }}}-t_{l_{\text {in }}}
\end{aligned}
$$

Here $\chi_{\text {conf }}$ is a known configuration parameter [13]. For the experimental conditions in the pure cross-flow compact heat exchanger $\chi_{\text {conf }}$ is typically $0.99 ; t_{l_{\text {in }}}$ represents the inlet coolant temperature and $Q_{c}$ the measured total heat flow rate to the coolant,

$Q_{c}=\left(w_{l} c_{p_{l}} t_{l}\right)_{\text {out }}-\left(w_{l} c_{p_{l}} t_{l}\right)_{\text {in }}$

The net heat flow resistance, $1 /\left(h_{g-l} \cdot A_{w}\right)$, depends on the heat transfer coefficient from the coolant to the plate at the coolant side, $h_{w_{l-g}}$, and the one through the plate of the gas, $h_{w_{l-g}}$ 
(see Fig. 7):

$\frac{1}{h_{g-1} \cdot A_{w}}=\frac{1}{h_{l-w_{l}} \cdot A_{l}}+\frac{1}{A_{w} \cdot h_{w_{l}-g}}$

Here $A_{l}$ denotes the total inner wall area in contact with the coolant. The coefficient $h_{l-w}$ is taken from a correlation [14] that accounts for the thermal entry length and yields $N u_{l}=2.98$ for very long channels. Its use is justified in the appendix. The heat transfer through the wall to the gas is described as that from an array of infinitely long cylinders through a plane wall to the gas. The expression used is given by Kutateladse [15]. Applied to the present geometry it reads ( $j$ appears as a dummy parameter that is introduced for ease of reference)

$h_{w}(j) \stackrel{\text { def }}{=} 1 / \frac{s}{k_{w} \pi} \cdot \ln \left(\frac{s}{S_{1}} \sinh \left(\frac{\pi \cdot[H+j]}{s}\right)\right)$

$s \equiv$ distance between two subsequent coolant channel cen ters $=1.67 \mathrm{~mm}$ (Fig. 1)

$H \equiv$ distance of coolant channel center to PVDF-gas surface $=1.0 \mathrm{~mm}$ (Fig. 1)

$S_{1} \equiv$ half the circumpherence of a coolant channel $=2.852 \mathrm{~mm}$

$h_{w_{i}-g} \stackrel{\text { def }}{=} h_{w}\left(j=\frac{k_{w}}{h_{g}}\right)$ see Eq. (7)

From Eqs. (3) through to (8) an expression for $h_{g}$ is easily derived in terms of parameters that can all be determined from experiments without condensation. The resulting values of $h_{g}$ are used to determine $a$ of Eq. (9) in a way to be described next

$N u_{g}=a+\tilde{f}\left(R e_{g}, P r_{g}, \frac{D_{H_{g}}}{B}\right)$

The function $\tilde{f}$ accounts for boundary layer development near the inlet. The following expression is used for our parallel plate geometry [16]

$$
\begin{aligned}
\tilde{f}= & 0.024 \cdot\left(\operatorname{Pr}_{g} \cdot \operatorname{Re} e_{g} \cdot\left(\frac{D_{H_{g}}}{B}\right)\right)^{1.14} / \\
& \left\{1+0.0358\left(\operatorname{Re}_{g} \operatorname{Pr}_{g} \frac{D_{H_{g}}}{B}\right)^{0.64} \operatorname{Pr}_{g}^{0.17}\right\}
\end{aligned}
$$

The term $a$ is fitted to experimental values of $h_{g}$ as discussed in the appendix. Equation (9) is henceforth employed to determine $N u_{g}$ with the $a$-values of Table 1 and the $\tilde{f}$-values of Eq. (10).

Table 1. Values of the coefficient $a$ of the sensible heat transfer correlation, obtained by fitting experimental data of measurements without condensation

\begin{tabular}{lllll}
\hline Cross-flow type & & Compartment & Re-range & $a$ \\
\cline { 1 - 1 } mixed & 1 & & & \\
mixed & 2 & {$[560,1030]$} & $5.21 \pm 0.2$ \\
pure & 1 & {$[560,1030]$} & $5.82 \pm 0.2$ \\
pure & 2 & {$[1700,2000]$} & $8.52 \pm 0.4$ \\
& & {$[1700,2000]$} & $7.83 \pm 0.4$ \\
\hline
\end{tabular}

The $a$ and $N u_{g}$ values for sensible heat transfer are used in subsequent computations of $t_{i}$ as argued at the end of Sect. 3.3

\section{4}

\section{Interfacial condensate temperature}

In this section, a way of computing interfacial temperatures from measured quantities is presented and results are compared with measured condensate temperatures. The wetted area fraction is needed in this method and is determined first. The interface temperature is essential for the condensate heat resistance computation of Sect. 5.

\section{1}

\section{Drainage and wetted area fraction}

The wetted area fraction, $\xi$, is defined as the projected interfacial area per unit condenser surface area, so $\xi=1$ for totally wetted and $\xi=0$ for totally dry surfaces. With special windows mounted on the sides of the heat exchanger, not shown in the figures, $\xi$ and drop size distributions have been measured. The dependancies of $\xi$ on $t_{g}$ and $c_{\text {in }}$ have been determined from cinerecordings and still photographs. The details of these observations are beyond the scope of the present paper and are reported elsewhere [5]. The experimental findings to be used in the present paper are summarised below.

Drops grow stagnantly on the plates; droplet growing after drop initiation is a quasi-steady process and is partially due to the coalescence of drops. Drainage happens via large drops rolling down the plate at an angle of ca. $30^{\circ}$ with the vertical while absorbing small drops on their way. Immediately after this drop passage a bare strip of the plate is exposed to the gas, as was reported for non-flow situations by others [3]. Many microscopic droplets are directly initiated on the dry patches.

Drop size distributions have been derived that are much similar to those on metal surfaces reported by others $[2,3]$. The maximum drop radius found, $R_{\max }$, is $2.25 \mathrm{~mm}$ and the smallest radius that could be detected is $0.05 \mathrm{~mm}$. The average radius of the drop base, $R$, is $0.30 \mathrm{~mm}$. It has been determined by $\int_{0}^{R_{\max }} r \cdot P(r) \cdot \mathrm{d} r$ with $P$ the normalised probability density function of radius $r$ that could safely be extrapolated from the measured values to the range $[0,0.05] \mathrm{mm}$. The wetted area fraction as determined from $\int_{0}^{R_{\max }} \pi r^{2} \cdot P(r) \cdot \mathrm{d} r$ turns out to be mainly determined by the larger drops.

For the prevailing cooling conditions, e.g. $t_{l_{i n}}=20^{\circ} \mathrm{C}, \xi$ has been found to be approximately independent of $R H_{g}$ and $t_{g}$ and with sufficient accuracy given by $0.45 \pm 0.1$.

The physicochemical properties of PVDF yield a computed static contact angle for water of $92^{\circ}$ which is in agreement with the approximately hemispherical shapes observed. The average height of the gas-condensate interface above the condenser plate is therefore equal to $\frac{\pi^{2}}{16} R$. This yields an average height, $\lambda$, of $0.185 \mathrm{~mm}$, independent of drop formation frequency and 
drop growth rate, hence independent of flow conditions; $\lambda$ will be used in Sect. 5 .

No change in contact angle has been observed during the experiments, nor any change in drop coalescence behaviour. It is therefore concluded that the wetting properties were not affected during the experiments.

\section{2}

\section{Interface temperature computation methods}

As discussed in the previous Sect. 3 the convective heat transfer to drops can be derived from the average Nusselt number, $N u_{g}$. The analogy of heat and mass transfer is employed to compute the average interface temperature. If the Nusselt number is given by Eqs. (9) and (10), the analogy between mass and heat transfer provides

$$
S h=a+b \cdot \tilde{f}\left(\operatorname{Re}_{g}, S c, \frac{D_{H_{g}}}{B}\right)
$$

Here $S h$ is the Sherwood number, $S h=g_{m} D_{H_{g}} /\left(\rho_{g} \mathbb{D}\right)$, with $g_{m}$ the mass transfer coefficient and $\mathbb{D}$ the diffusion coefficient of water vapor in air; $S c$ is the $S c h m i d t$ number, $S c=\eta_{g} /\left(\rho_{g} \mathrm{ID}\right)$.

The local condensate flux, $\dot{m}_{c}$, is according to classical film ${ }^{4}$ theory given by [1]

$$
\dot{m}_{c}=-\frac{\operatorname{Sh} \rho_{g} \mathbb{D}}{D_{H_{g}}} \ln \left(\frac{1-c_{b}}{1-c_{i}}\right)
$$

Here $c_{b}$ denotes the bulk concentration of vapor in the mean flow between the parallel plates and $c_{i}$ the vapor concentration at the interface; $S h$ is determined by Eq. (11) and the correlations of the appendix. The interface temperature follows directly from $c_{i}$ via the saturation line. The saturated water vapor pressure follows from the Antoine relation [13].

In computing the average condensate mass flux, $\dot{m}_{c}$, from the mass flow rate measured, $W_{c}$, it is necessary to employ the appropriate area of contact for diffusion. It is $2 \xi A_{w}$ since each droplet has a contact angle of about $92^{\circ}$ (see Sect. 4.1) and since the area in contact with gas of a hemispherical drop, $2 \pi R^{2}$, is twice the area of its base, $\pi R^{2}$. With $c_{b}$ replaced by $\bar{c}_{b}$, the average of the measured $c_{b_{\text {in }}}$ and $c_{b_{\text {our }}}$, Eq. (12) yields the average value of the interfacial vapor concentration, $c_{i}$, and hence the average interface temperature, $t_{i}$.

Another, independent way for determining the mean interface temperature is based on sensible heat transfer and requires some knowledge of the spatial variation of the Nusselt number which is all but trivial. This method has been shown [7] to yield similar results as the method described above if heuristically some Nusselt number variation is assumed.

\section{3}

\section{Computed interfacial temperatures of the condensate}

Figure 8 shows interface temperatures computed for the mixed cross-flow experiments. It is clearly seen that generally interface temperatures obtained are not far from the measured con-

4 Note that the term 'film' here denotes the inert gas layer close to the cold surface and has nothing to do with the condensate shape.

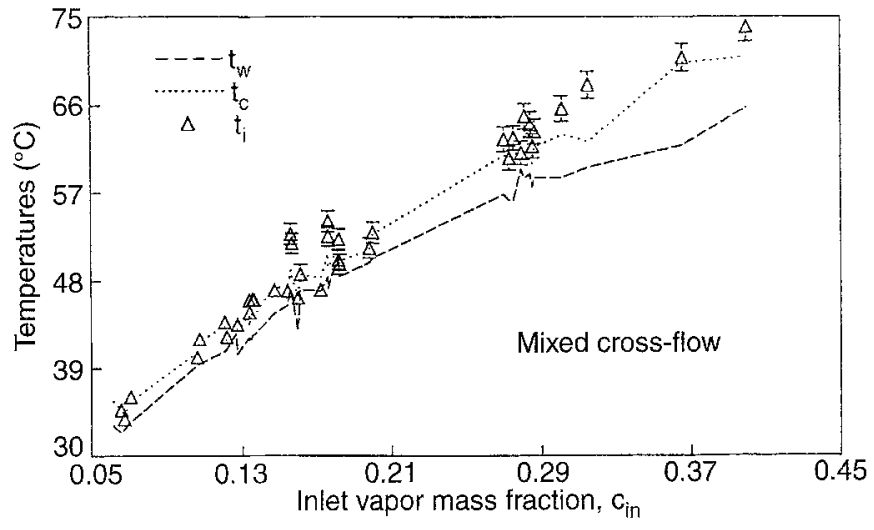

Fig. 8. Comparison of computed interface temperatures with measured condensate temperatures and derived wall temperatures

densate temperatures as is to be expected. The inlet vapor mass fraction, $c_{\text {in }}$, has been selected for presentation of the main results of sections 4.3 and 5 since $c_{\text {in }}$ is an input parameter with a value that is varied at will by varying either $R H$ or $t_{g_{\text {in }}}$ and since the vapor mass fraction governs the condensate flux according to Eq. (12) if all coolant parameters and the gas mass flow rate are kept constant.

Let $\bar{t}_{i} \stackrel{\text { def }}{=} \frac{1}{2}\left(t_{l_{\text {in }}}+t_{l_{\text {out }}}\right)$ and let $h_{w_{1}-w} \stackrel{\text { def }}{=} h_{w}(0)$. The average plate temperature on the gas side, $t_{w}$, is determined from Eq. (13):

$\frac{\left(t_{w}-\bar{t}_{l}\right)}{Q_{c}}=\frac{1}{h_{l-w_{l}} \cdot A_{l}}+\frac{1}{A_{w} \cdot h_{w_{l}-w}}$

with $Q_{c}$ given by Eq. (5). Values for $t_{w}$ obtained with Eq. (13) are given in Fig. 9. The result $t_{i}>t_{c}>t_{w}$ of Fig. 9 is as expected. The difference $t_{c}-t_{w}$ is found to increase with increasing inlet vapor concentration, $c_{\mathrm{in}}$, just as the difference $t_{i}-t_{w}$.

A sensitivity analysis has been carried out by varying the input parameters that determine $t_{i}$. A variation of the wetted area fraction, $\xi$, by $\pm 20 \%$ varied $t_{i}$ only by $\pm 3 \%\left( \pm 1.5^{\circ} \mathrm{C}\right)$. A

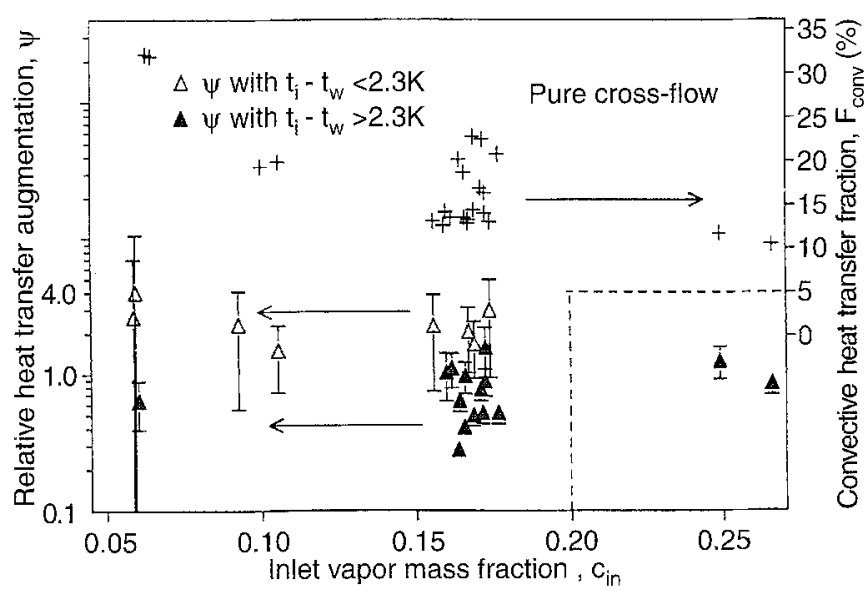

Fig. 9. Convective heat transfer fraction and relative condensate heat transfer augmentation, $\psi$, versus inlet vapor mass fraction for the pure cross-flow measurements. The dotted lines are for ease of reference to Fig. 10 
variation of $t_{g_{\text {in }}}$ by $\pm 3 \%$ changed $t_{i}$ by ca. $\pm 2 \%\left( \pm 1^{\circ} \mathrm{C}\right)$. In view of the accuracy of $\xi$ (ca. $\pm 10 \%$ ) and the measurement accuracy of $t_{g_{\text {in }}}(0.8 \%)$ these results are satisfying.

\section{5}

\section{The heat resistance of the condensate}

In this section the heat resistance of the condensate is quantified with the aid of the interface temperatures determined in Sect. 4.3 .

The convective heat transfer fraction, $F_{\text {conv }}$, defined by

$F_{\text {conv }} \stackrel{\text { def }}{=}\left\{Q_{g}-W_{c} \cdot e_{v}\left(t_{i}\right)\right\} / Q_{g}$

In some measuring conditions there is a significant contribution of sensible heat to the total heat flow rate. This is especially so for relatively low $c_{\text {in }}$ and for the relatively high gas velocities of the pure cross-flow experiments, see Figs. 9 and 10. Since the scales in these two figures are different, it is tried to facilitate comparison by means of the dotted lines. The sensible heat transfer must therefore be accounted for in the determination of the heat transfer coefficient of the condensate, $h_{c}$, from $Q_{c}$.

A first estimate of this heat resistance is $\lambda / k_{c}$ with $\lambda$ the average condensate height, see Sect. 3.2. In order to account for isothermals being not perfectly parallel to the wall and for possible reduction of heat resistance due to thermocapillary convection in the condensate a parameter, $\psi$, is introduced:

$h_{c}=\psi \cdot k_{c} / \lambda$

Thermocapillary driven convection is due to surface tension gradients and is to be expected whenever temperature gradients occur at the interface of very clean water. Zhang and Yang [6], in an interesting experiment, demonstrated the occurrence of this so-called Marangoni convection in drops adhering to partially heated surface. Note that the induced flow is from low surface tension regions to high surface tension regions.

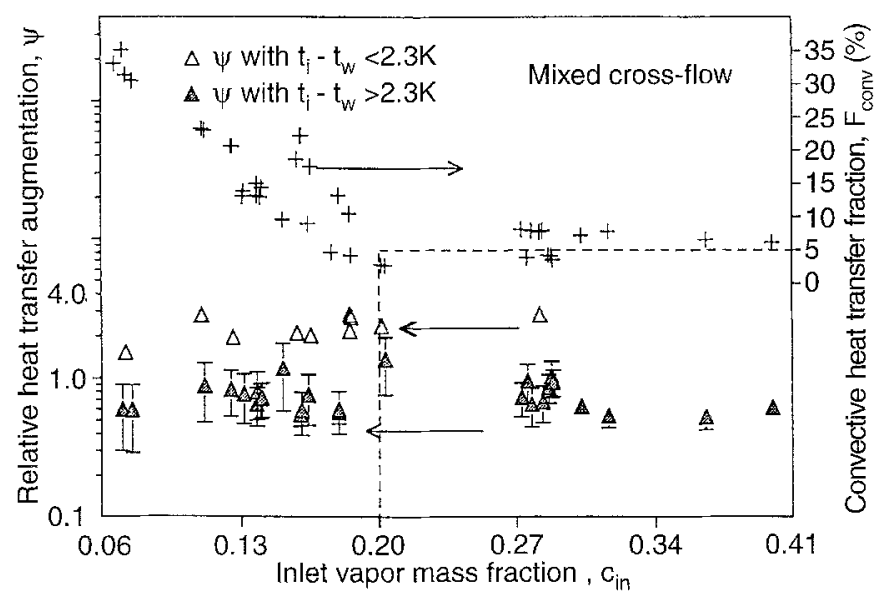

Fig. 10. Convective heat transfer fraction and relative condensate heat transfer augmentation, $\psi$, versus inlet vapor mass fraction for the mixed cross-flow measurements. The dotted lines are for ease of reference to Fig. 9
Let $h_{w i-i} \stackrel{\text { def }}{=} h_{w}\left(j=k_{w} / h_{c}\right)$, see Eq. (7), denote the heat transfer coefficient through the wall and through a drop to the gasliquid interface. It is determined from Eq. (14) describing heat transfer via dry patches as well as via the condensate (see also Fig. 7):

$$
\begin{aligned}
Q_{c}= & (1-\xi) \cdot\left(\frac{1}{h_{l-w_{l}} \cdot A_{l}}+\frac{1}{h_{w_{l}-w} \cdot A_{w}}\right)^{-1} \cdot\left(t_{w}-\bar{t}_{l}\right) \\
& +\xi \cdot\left(\frac{1}{h_{l-w_{l}} \cdot A_{l}}+\frac{1}{h_{w_{l}-i} \cdot A_{w}}\right)^{-1} \cdot\left(t_{i}-\bar{t}_{l}\right)
\end{aligned}
$$

A typical value of $h_{l-w_{t}}$ is $1100 \mathrm{~W} / \mathrm{m}^{2} \mathrm{~K}, h_{w-w}$ is typically $900 \mathrm{~W} / \mathrm{m}^{2} \mathrm{~K}$ and $h_{c}$ is approximately $k_{c} / \lambda=0.60 / 0.185 \approx$ $3200 \mathrm{~W} / \mathrm{m}^{2} \mathrm{~K}$.

Since $Q_{c}$ and $\bar{t}_{l}$ are directly measured and $t_{i}$ and $t_{w}$ are determined in ways described above, see Sect. 4.2 and Eq. (13), the value of $h_{w_{l-i}}$ can be determined from Eq. (14). From $h_{w_{t-i}}$ the values of $j$ and hence $h_{c}$ and $\psi$ are derived.

Figures 9 and 10 summarise the results for the relative condensate heat transfer augmentation, $\psi$, for pure and mixed cross-flow respectively. The error in $\psi$ is due to errors in $t_{w}$ $(2 \%), t_{i}(2 \%), Q_{g}(3 \%)$ and in other parameters. As a general rule, the error in $\psi$ is large if the temperature drop $\left(t_{i}-t_{w}\right)$ is small. In Fig. 9 this is clearly seen since the data with $\left(t_{i}-t_{w}\right)$ less than $2.3^{\circ} \mathrm{C}$ are designated by a different symbol.

It appears that $t_{i}$ is more also to the wall temperature for relatively low inlet vapor concentrations, $c_{i n}$. This is also true for the mixed cross-flow results of Fig. 10. In this figure the error bars for the data with $\left(t_{i}-t_{w}\right)<2.3^{\circ} \mathrm{C}$ are omitted for sake of clarity.

Within the measurement accuracy no systematic dependence of $\psi$ on $c_{\text {in }}$ is detected, nor on inlet humidity or inlet gas temperature or any other parameter. This may be partly due to the sometimes relatively large errors.

The average value of the heat transfer augmentation ratio is for the mixed cross-flow $1.18 \pm 0.25$ (95\% accuracy for 37 data) if not weighted by the errors. This way of averaging is more appropriate than the weighted averaging procedure for the following reason. The interface temperature computation starts from the gas temperature whereas the wall temperature computation starts from the mean coolant temperature. If the actual values of $t_{i}$ and $t_{w}$ are close the accuracy of both methods of computation must be large in order to really obtain the actual $\left(t_{i}-t_{w}\right)$. If due to the errors involved the computed value of $t_{i}$ becomes irrealistically close to that of $t_{w}$ the computation of $\psi$ fails. For this reason only $23 \psi$-values are obtained for 33 pure cross-flow experiments. This causes an artificial unbalance in the resulting set of $\psi$-values in favor of the data with $\left(t_{i}-t_{w}\right.$ ) exceeding $2.3^{\circ} \mathrm{C}$ which can only be compensated for by not weighting the errors. The numerical computations of Sect. 3.2 indicate that the average temperature drop would be about $2.2^{\circ} \mathrm{C}$. However, in Figs. 9 and $10\left(t_{i}-t_{w}\right)$ exceeds $2.3^{\circ} \mathrm{C}$ for more than $60 \%$ of the data. This adds to the belief that the set of $\psi$-values is not well balanced.

The unweighted pure cross-flow average is $1.37 \pm 0.42(95 \%$ accuracy for 23 data).

Summarising, it is concluded that the relative condensate heat transfer augmentation, $\psi$, is $1.3 \pm 0.3$. Hence, Marangoni convection might affect heat transfer in the plastic heat exchanger in the presence of flowing, inert gases. 


\section{Conclusions}

Condensation experiments with a mixture of air and steam flowing in two plastic compact heat exchangers have been performed. The condensation occurred dropwise due to a contact angle of $\mathrm{ca} .90^{\circ}$ and the use of clean gases and clean, flat condenser plates. The main goal of the measurements has been the determination of the condensate heat resistance for various process conditions. The measurement accuracies of condensate mass flow rate, $W_{c}$, and of the vapor concentrations at the inlet and the outlet are assessed by comparing two independent means of measuring $W_{c}$; a good agreement was found. The measured heat flow rates from the gas and to the liquid (coolant) show good agreement.

A procedure is presented to derive the average condensategas interface temperature, $t_{i}$, from parameters measured at inlet and outlet since $t_{i}$ is important for the computation of the condensate heat resistance. In this procedure the condenser plate area covered by drops and the Sherwood number appear. The first is determined from visualisations and the latter is determined from the average Nusselt number because of the analogy of heat and mass transfer. It is shown that the average convective heat flux to a wall covered with condensate drops can be derived from the mean value of the Nusselt number as measured in experiments without condensation. This is done by demonstrating that no large gas flow oscillations occur implying that the vortex structures in the wakes of the hemispherical drops are stagnant and by referring to direct, local measurements by others [9] in similar flow conditions. The stability of the flow is deduced from finite element computations and from a comparison of pressure drop measurements with and without drops. The average Nusselt numbers without condensation are measured and show good agreement with correlations available in the literature.

The computed interface temperatures are consistent with measured mixed cup condensate temperatures, $t_{c}$, and with computed wall temperatures, $t_{w}$. The difference $t_{c}-t_{w}$ is found to increase with increasing inlet vapor concentration, $c_{\mathrm{in}}$, just as the difference $t_{i}-t_{w}$.

The computed temperatures are used to calculate the mean condensate heat transfer resistance. The sensible heat transfer can be as large as $35 \%$ of the total heat transfer for low $c_{\text {in }}$ (ca. 0.07 ) and has been taken into account in the analysis. The value of the condensate heat resistance is approximately given by $\lambda / k_{c}$ with $k_{c}$ the heat conduction coefficient of water and $\lambda$ the measured mean height of the condensate-gas interface above the wall (ca. $0.185 \mathrm{~mm}$ ). Although there is room for increasing the accuracy of the measurements, as shown below, the present analysis indicates that the mean condensate heat resistance is probably less than $\lambda / k_{c}$ by a factor of about $0.8 \pm 0.2$. This may be due to thermocapillary convection in the drops.

The accuracy of this result could be improved by measuring the temperatures of the condensate and the wall directly by a non-intrusive technique.

\section{References}

1. Brouwers, H. J. H.; Geld, C. W. M. van der: Heat transfer, condensation and fog formation in crossflow plastic heat exchangers. Int. J. Heat Mass Transfer (1995), to appear
2. Tanaka, H.: Measurement of drop-size distributions during transient dropwise condensation. Trans. ASME, J. Heat Transfer 97 (1975) $341-346$

3. Krischner, S.; Grigull, U.: Mikroskopische Untersuchung der Tropfenkondensation. Wärme- und Stoffübertragung 4 (1971) 48 -59

4. Brouwers, H. J. H.: Pure steam condensation experiments on nonisothermal vertical plates. Trans. of the ASME, J. of Heat Transfer 114 (1992) 714-718

5. Ganzevles, F. L. A.; Geld, C. W. M. van der: In situ measurements of wetting rate and local temperatures with dropwise condensation in a compact heat exchanger. Submitted for the Proc. of the 24th National Heat Transfer Conf., Symp. Compact Heat Exchanger Technology, Portland, O.R., MKJ-5 (1995) 8

6. Zhang, M.; Yang, W.: Evaporative convection in minute drops on a plate with temperature gradients. Int. J. Heat Mass Transfer 26 (10) (1983) $1479-1488$

7. Geld, C. W. M. van der: Dropwise condensation of air-steam mixtures in a PVDF compact heat exchanger. Conf. paper of the European Two-Phase Flow Group Meeting. Hannover, Report WOCCMHT 2102.21, Eindhoven Univ. of Techn. (1993) 44

8. Kline, S. J.; McClintock, F. A.: Describing uncertainties in singlesample experiments. Mech. Eng. 75 (1953) 3-8

9. Fiebig, M.; Grosse-Gorgemann, A.; Hahne, W.; Leiner, W.; Lorentz, S.; Mitra, N. K.; Weber, D.: Local heat transfer and flow structure in grooved channels: measurements and computations. Proc. of the Tenth Int. Heat Transfer Conf. 4 8-IC-8 (1994) 237-241

10. Hu, X.; Zhang, L.; Jacobi, A. M.: Surface irregularity effects on droplets and retained condensate on local heat transfer to finned tubes in cross-flow. ASHRAE Trans.: Research 100 (1994) 375-381

11. Shah, R. K.; London, A. L.: Laminar flow forced convection in ducts. London: Academic Press, page 163 and page 200, 1978

12. Brouwers, H. J. H.; Chesters, A. J. K.: Film models for transport phenomena with fog formation: the classical film model. Int. J. Heat Mass Transfer 35 (1992) $1-11$ and 2067

13. V.D.I.: V.D.I.-Wärmeatlas (5. Aufl.), Düsseldorf: V.D.I. Verlag GmbH (in German), page Ca18 (Bild 10) and Ca20 (Bild 14) 1988

14. Dennis, S. R. C.; Mercer, A. M.; Poats, G.: Forced heat convection in laminar flow through rectangular ducts. Quart. Appl. Math 17 (1959) 285-297

15. Kutateladse, S. S.: Fundamentals of heat transfer. London: Edward Arnold, page 92, 1963

16. Stephan, K.: Wärmeübertragung und Druckabfall bei nicht ausgebildeter Laminarströmung in Rohren und in ebenen Spalten (in German). Chemie-Ing.-Techn. 31 (1959) 773-778

\section{Appendix}

\section{Sensible heat transfer correlations}

Experiments without condensation are used to quantify the convection heat transfer from the coolant to the gas side of the condenser plate, $h_{l-g}$, in a way described in section 3.4. The results are correlated in this appendix by determining the constant $a$ in Eq. (9). The correlation used for the convective heat transfer coefficient from the coolant to the PVDF plate, $h_{l-w_{i}}$ (Fig. 7), was derived for a constant inner coolant wall temperature, $t_{w_{l}}[14]$. It is examined in this appendix if its use is justifiable.

Table 1 summarises the values for a obtained. The error in this table denotes the $95 \%$ reliability interval based on 7 data (mixed cross-flow) and 9 data (pure cross-flow). These $a$ values do not systematically depend on the gas Reynolds number, $R e_{g}$, so Stephan's inlet correction is likely to be satisfactory.

If $t_{w 1}$ is not constant this is accounted for by the value of $a$. For uniform wall temperature $a=7.55$. For uniform heat flux with nonuniform wall temperature along a cross-section $a$ is less [11]. Here $a$ is expected to be less than 7.6 since without condensation the gas side plate temperatures, $t_{w}$, are not uni- 
form. The mixed cross-flow experiments have been carried out with a relatively low coolant mass flow rate, $W_{l}=0.156 \mathrm{~kg} / \mathrm{s}$, $R e_{g} \sim 900$, in order to have a large temperature drop from outlet to inlet of the coolant to enhance accuracy of the measurement of the coolant temperature increase. The plate temperatures have in this case indeed been nonuniform and $a$ values are consequently below 7.55 .

For the pure cross-flow experiments, coolant mass flow rate is $0.45 \mathrm{~kg} / \mathrm{s}, R e_{g} \sim 1800, N u_{l}=3.4$, which explains the bigger spread in the results (coolant temperature increase is less and hence more difficult to measure) and also the higher $a$ values (constant temperature approximation is better satisfied). Here $a$ is between the values corresponding to uniform heat flux $(a=8.24)$ and uniform temperature $(a=7.55)$.
Pitot tubes were used to measure local velocities in both compartments. No differences were found so the gas flow is split up symmetrically. Differences in gas Nusselt values of the two cross-flow types may be due to a slightly different coolant inlet, different thermal insulation or due to the mixing of coolant halfway the mixed cross-flow geometry.

It is concluded that the use of the correlation for $h_{l-w}$ is justified since the parameter $a$ accommodates the possible variation of $t_{w t}$ and has experimentally been determined for the proper flow conditions. Since temperatures vary in flow direction [1] the use of the above correlations in a method for interface temperature determination is justified. 